\title{
Evolution of the Surface Science of Catalysis from Single Crystals to Metal Nanoparticles under Pressure
}

\author{
Gabor A. Somorjai ${ }^{1,2, *}$ and Jeong Y. Park ${ }^{1,2}$ \\ ${ }^{1}$ Department of Chemistry, University of California, Berkeley, CA 94720 \\ ${ }^{2}$ Materials Sciences Division and Chemical Sciences Division, Lawrence Berkeley \\ National Laboratory, Berkeley, CA 94720
}

\begin{abstract}
Vacuum studies of metal single crystal surfaces using electron and molecular beam scattering revealed that the surface atoms relocate when the surface is clean (reconstruction) and when it is covered by adsorbates (adsorbate induced restructuring). It was also discovered that atomic steps and other low coordination surface sites are active for breaking chemical bonds $(\mathrm{H}-\mathrm{H}, \mathrm{O}=\mathrm{O}, \mathrm{C}-\mathrm{H}, \mathrm{C}=\mathrm{O}$ and $\mathrm{C}-\mathrm{C})$ with high reaction probability. Investigations at high reactant pressures using sum frequency generation (SFG) - vibrational spectroscopy and high pressure scanning tunneling microscopy (HPSTM) revealed bond breaking at low reaction probability sites on the adsorbatecovered metal surface, and the need for adsorbate mobility for continued turnover. Since most catalysts (heterogeneous, enzyme and homogeneous) are nanoparticles, colloid synthesis methods were developed to produce monodispersed metal nanoparticles in the 1-10 $\mathrm{nm}$ range and controlled shapes to use them as new model catalyst systems in twodimensional thin film form or deposited in mesoporous three-dimensional oxides. Studies
\end{abstract}


of reaction selectivity in multipath reactions (hydrogenation of benzene, cyclohexene and crotonaldehyde) showed that reaction selectivity depends on both nanoparticle size and shape. The oxide-metal nanoparticle interface was found to be an important catalytic site because of the hot electron flow induced by exothermic reactions like carbon monoxide oxidation.

*To whom correspondence should be addressed. E-mail:somorjai@berkeley.edu 


\section{Introduction}

In our view, the field of catalysis could be analogous to an onion with shells and a core as illustrated in Figure 1. The outer shell represents technology, process control and reactor design; the layer in the middle where synthesis and fabrication of catalysts and the techniques and instrumentation to characterize catalysts are located along with studies of deactivation and regeneration and of course macroscopic kinetics. In the core of this onion are molecular studies to understand the molecular mechanisms of structure bonding and dynamics ${ }^{[1-3]}$, how the three types of catalyst systems (enzyme, heterogeneous and homogeneous) work. It is this molecular core that we aim to address in this paper.

The common property of all three-catalyst systems that is most apparent is that they are all nanoparticles. For example, Cytochrome C, which is one of the over 3000 enzymes that functions in the human body (Figure 2a) is $4 \mathrm{~nm}$ in size with its protein shell wrapped around it. The primary structure of Cytochrome C consists of a chain of 100 amino acids, and its molecular weight is 12,000 daltons ${ }^{[4]}$. The size of its active site (heme) in the enzymatic process is $1.4 \mathrm{~nm}^{[5]}$. A typical homogeneous catalyst used for olefin polymerization is a so-called single site catalyst with an active site that is a titanium ion surrounded by ligands (Figure $2 \mathrm{~b}$ ), which is $1.6 \mathrm{~nm}$ in size ${ }^{[6]}$. This nanosize molecule produces a million C-C bonds as it makes polypropylene ${ }^{[7]}$. The heterogeneous catalysts such as platinum nanoparticles (Figure 2c) are between 1-10 nm in size ${ }^{[8]}$. In the figure we show a method to synthesize these monodispersed nanoparticles with the desired size and shape that may be cubes or cuboctahedra ${ }^{[9]}$. 
Over forty years, tremendous efforts were made to aim at understanding the properties of surfaces, structure, composition, dynamics on the molecular level and at developing the surface science of heterogeneous catalysis using the knowledge accumulated $^{[2,3,10-13]}$

Surfaces are three types; external surfaces such as single crystals shown in Figure 3a; internal surfaces are shown in Figure $3 b$ where most of the surface area is located inside the micropores or mesopores ${ }^{[14-20]}$, and these surfaces may contain metal nanoparticles for catalytic purposes; the nanoparticles, as shown in Figure 3c, are the third type of surface. In this figure we show nanoparticles of platinum made by electron beam lithography or nanoparticles synthesized in colloidal solutions with well-defined size in the $1-10 \mathrm{~nm}$ regime and shape ${ }^{[9,21]}$. We show here a cubic nanoparticle.

The evolution of modern surface science started in vacuum using single crystal surfaces (Figure 4). In vacuum, or at low pressures that permit high enough mean free paths for the exiting particle surface probes to be detectable, one could determine the surface composition with less than $1 \%$ of a monolayer sensitivity, electronic structures and oxidation states of surface atoms, and the surface structures of clean surfaces and adsorbed atoms and molecules with their bond distances and bond angles ${ }^{[1]}$. Usually, single crystals were used in these studies that served as model surfaces, and there were major discoveries in the vacuum surface science era ${ }^{[22-24]}$.

Low energy electron diffraction studies quantitatively showed the bond distances, bond angles and locations of adsorbed molecules such as ethylene on the platinum and rhodium (111) crystal faces ${ }^{[25,26]}$. Figure 5 shows that the bond order of the organic 
molecule decreases and the metal atoms around the adsorbed molecule move, which is called adsorbate-induced surface restructuring, to optimize the strength of the surface chemical bonds. Figure 6 shows the results of molecular beam scattering studies of $\mathrm{H}_{2}$ $\mathrm{D}_{2}$ exchange that indicated that atomic steps on metal surfaces break chemical bonds, in this case hydrogen-hydrogen bonds, with unit reaction probability ${ }^{[27]}$. In the same time flat, low Miller Index (111) platinum surfaces do not break $\mathrm{H}_{2}$ bonds on single scattering, and the reaction probability is lower than the detection limit ${ }^{[28]}$. Flat, high density clean surfaces of many substances also restructure where the surface atoms move into new locations. These are shown for platinum ${ }^{[29]}$ and sodium chloride ${ }^{[30]}$ in Figure 7.

\section{Surface science under high pressure}

Surfaces can carry out many chemical reactions, among them catalytic reactions are the most prominent. However, these reactions could not be studied in vacuum because of the very low reaction probability that inhibit their detection ${ }^{[31]}$. We have developed surface science techniques that could be used under pressure, among them the two most frequently; sum frequency generation (SFG) vibrational spectroscopy and high pressure scanning tunneling microscopy.

SFG vibrational spectroscopy is a surface specific technique that was developed in Berkeley, and its roots lie in second harmonic generation ${ }^{[32,33]}$. One or both laser frequencies are tuned and spatially and temporally overlapped. By scanning one of the lasers in the infrared frequency regime we could obtain a sum frequency signal, and thus a vibrational spectra in the visible as shown in Fig. 8a. Such a signal is forbidden from a 
centrosymmetric medium such as the bulk of face centered cubic crystals or an isotropic high pressure gas or a liquid. However, at the surface the second order susceptibility of non-zero is allowed, and the surface yields vibrational spectrum that is monolayer sensitive. It is also able to give us vibrational frequencies of adsorbed molecules in 10-12 orders of magnitude in pressure ranges ${ }^{[11]}$. This is shown from carbon monoxide and ethylene where the vibrational spectra are virtually pressure independent for molecules adsorbed on the metal surface (Figures $8 b)^{[34]}$.

The schematic of high pressure STM is shown in Fig. 9a ${ }^{[35-37]}$. Although most researchers use this technique at low pressures, when it is used around 200 Torr one can see ordered surface structures of carbon monoxide that are not seen at low pressures as shown in Figure $9 b^{[35]}$. Due to a close packing of these molecules on the surface, there is an increase in repulsive interaction among molecules that leads to ordering which is not observable at low pressures. Another surface phenomena caused by the increased coverage under pressure is reconstruction of the surface, and this is shown in Figure 10. The adsorbates change the surface structure differently, as shown for oxygen, hydrogen and carbon monoxide in this figure ${ }^{[38]}$.

The high pressure also allows access to low reaction probability sites. This is shown for the $\mathrm{C}-\mathrm{H}$ dissociation of methane on the platinum (111) surface, which has a very low reaction probability that is one in a hundred million methane molecule upon incidence on the platinum surface would dissociate (Figure 11a) ${ }^{[39]}$. It is immeasurable in vacuum but at one Torr of methane pressure, after 60 seconds vibrational spectroscopy can detect $\mathrm{CH}$ and other fragments that form on the metal surface (Figure 11b). 


\section{Catalysis under Pressure}

Our new techniques, SFG vibrational spectroscopy and high pressure STM, permitted us to monitor surface reaction intermediates and the dynamics of molecules on surfaces, or surface mobility ${ }^{[40]}$. Three species on the Pt (111) surface; ethylidyne, di- $\sigma-$ ethylene and $\pi$-bonded ethylene were detected by vibrational spectroscopy under highpressure ethylene hydrogenation ${ }^{[41]}$. Only the latter, that is most weakly held, is turning over during catalytic reaction. The other two species are stagnant on the surface, strongly adsorbed and spectators, during catalysis. Another reaction, cyclohexene hydrogenation/dehydrogenation, forms three reaction intermediates on the surface at high pressures that are detectable as shown in Figure 12a. Equally interesting is when we scan the surface under ethylene hydrogenation conditions or under cyclohexene hydrogenation/dehydrogenation during the reaction turnover, we see no scanning tunneling microscopy pictures. Large scale images $(\sim 1000 \AA)$ still reveal the same platinum steps regularly observed, but no molecular surface structure can be resolved in small scale images $(\sim 75 \AA)$ as shown in Figure $12 b^{[42]}$. This indicates that the adsorbed monolayer of molecules and atoms is now too mobile to image with the STM. The maximum scanning speed at which images can be obtained is $10 \mathrm{~nm} / \mathrm{msec}$, but several scans may be necessary to image an entire molecule. Molecules that diffuse or adsorb/desorb on a faster time scale than this were not able to be resolved. The formation of this mobile overlayer also corresponds to the onset of catalytic activity as monitored by the mass spectrometer. Once the reaction stops, because of the poisoning of the surface with carbon monoxide, ordered structures form and there is no reaction product 
formation (Figure 12c). The production of cyclohexane and benzene produced by the hydrogenation and dehydrogenation of cyclohexene on the catalytically active $\operatorname{Pt}(111)$ and $\mathrm{CO}$ poisoned $\mathrm{Pt}(111)$ was measured by mass spectrometer. The mobility of adsorbates on the surface is important to allow the freeing up of active sites that are being covered on the crowded surfaces under reaction conditions.

\section{Studies of catalytic activity and selectivity with single crystal metal surfaces}

\section{and nanoparticles.}

Catalysis in the $21^{\text {st }}$ Century focuses on reaction selectivity ${ }^{[43]}$. Our model single crystal catalysts cannot possibly identify all the active sites that are important to describe catalytic selectivity, as the catalysts are nanoparticles usually supported on oxide surfaces. Therefore, we undertook the development of model nanoparticles by electron beam lithography, photolithography ${ }^{[44]}$, and finally, which was the most successful, using colloid chemistry controlled nanoparticle synthesis. Catalysts are in the 1-10 nm range, and their shape, whether they are cubic or hexagonal, is very important in controlling selectivity as well as activity. Our focus was on rhodium and platinum nanoparticles that can be produced with monodispersity and well-controlled shape. Using rhodium acetyl-acetonate or hexachloro platinic acid as a precursor monomer, we could produce monodispersed metal nanoparticles, each one coated with a polymer cap that prevents aggregation in solution ${ }^{[9,45]}$. These nanoparticles can be placed on a Langmuir-Blodgett trough and pulled as a monolayer film at various densities as shown in Figures $13^{[9,46]}$. Conversely they can be incorporated in mesoporous high surface area 
oxides such as SBA-15 ${ }^{[16,17,47]}$. The electron microscope picture of the nanoparticles so dispersed in a 3-dimensional medium is shown in Figure 14.

The selectivity of multipath reactions such as benzene hydrogenation or cyclohexene hydrogenation has been studied as a function of nanoparticle size or shape. Figure 15 shows a comparison of product selectivity as a function of shape for platinum single crystal vs. platinum nanoparticle surfaces ${ }^{[48]}$. The (111) face of platinum single crystal produces two molecules; cyclohexane and cyclohexene, so do the hexagonal nanoparticles of platinum. The (100) face of platinum single crystals produces only cyclohexene, as do the cubic nanoparticle structures. Thus, for this example, selectivity of nanoparticles and single crystals of the same surface structure are the same.

Figure 16a shows the size-dependence of the turnover rate for cyclohexene hydrogenation vs. dehydrogenation to cyclohexene or benzene, respectively ${ }^{[8]}$. Because the activation energy for dehydrogenation is increasing as a function of particle size (Figure 16b), the product selectivity is altered and the benzene yield is decreasing as a function of increasing particle size. Thus this multipath reaction is size sensitive. So is crotonaldehyde hydrogenation as shown in Figure 17, which shows a decrease in butyraldehyde production as compared to crotyl alcohol with increasing particle size.

It is possible to synthesize bimetallic nanoparticles of platinum/rhodium with monodispersed size. Since the turnover rate for rhodium nanoparticles is about 20 times higher for $\mathrm{CO}$ oxidation as compared to the turnover rate of platinum nanoparticles, the bimetallic system shows increasing turnover rate with increasing rhodium concentration 
in the bimetallic particles ${ }^{[49]}$. Thus, one can tailor the turnover rate of CO oxidation by changing the platinum to rhodium ratio in these nanoparticles.

\section{Oxide metal interfaces are catalytically active}

It has been a longstanding observation in the field of heterogeneous catalysis that the oxide onto which the metal nanoparticles are deposited can dramatically change the activity and selectivity in certain reactions even though the oxide itself is not active in catalysis ${ }^{[50,51,52]}$. Recently studies, which detected hot electron formation at metal surfaces helped to explain these curious findings ${ }^{[53-55]}$. By pulse probe experiments, one could detect hot electron formation within the femtoseconds when photons are incident on a metal surface. Experiments indicate that a mean free path is in the order of $5 \mathrm{~nm}$ for these hot electrons, which is in the range of the size of catalyst nanoparticles. Further studies indicated that exothermic catalytic reactions can also produce hot electrons readily, for example $\mathrm{CO}$ oxidation or the reaction of hydrogen and oxygen to form water. We have constructed "catalytic nanodiode" in our laboratory ${ }^{[56-58]}$ whereby we carry out catalytic reactions at high and continuous turnover and, using a Schottky-barrier the hot electrons are collected as shown in Figure 18. When the turnover rates for CO oxidation, for example, is measured continuously in the same time, the hot electron current is measured and the hot electron current and the turnover rate for the reaction are correlated $^{[58]}$. This implies that the activity at the oxide metal surface in certain catalytic reactions which is often called as "strong metal-support interaction [59-61]" can be associated with the hot electron flow at oxide-metal interface. 


\section{Challenges and Future Directions}

It is necessary that we can use our techniques, SFG and STM, to monitor nanoparticles as they undergo reactions, just as we monitored single crystal surfaces during chemical reactions ${ }^{[62]}$. Preliminary studies indicate that we cannot image the metal nanoparticles with STM because of the polymer capping. Work is in progress to remove the polymer capping to prepare the naked nanoparticles for STM studies.

Figure 19 shows that, using the Kirkendall effect ${ }^{[63]}$, we can produce nanoparticles of hollow oxides, such as cobalt oxide if the outdiffusion of cobalt is faster than the indiffusion of oxygen during oxidation of cobalt nanocrystals. If we use a platinum nanoparticle and cap it with a hollow cobalt oxide, in effect, we can make a nanoreactor in which each platinum nanoparticle is surrounded by a shell of an oxide ${ }^{[64]}$. Reaction study of ethylene hydrogenation indicates that molecules can penetrate the porous oxide shell and undergo reactions on platinum and then the products can leave. Such a core shell structure could be produced having a mesoporous oxide shell and a catalyst metal particle in the center. These types of systems may lead to the production of novel bifunctional catalysts ${ }^{[49]}{ }^{[65]}$ with unique reactivity or selectivity.

Finally, the grand challenge of catalysis is combined molecular studies of homogeneous, heterogeneous and enzyme catalysts. In order to understand on a molecular level how the workings of these three types of catalysts (heterogeneous, homogeneous and enzyme) correlate, our challenge is that these should be studied under identical or similar experimental conditions. Because of the limitations of enzyme 
temperature sensitivity all three catalysts should be studied at around $300 \mathrm{~K}$ and in water. It is hoped that when all three-catalyst groups are studied under similar experimental conditions, we shall take a major step toward understanding the molecular ingredients of the catalyst nanosystems that make them so important in reaction turnover and reaction selectivity.

\section{Acknowledgement}

This work was supported by the Director, Office of Science, Office of Advanced Scientific Computing Research, Office of Basic Energy Sciences, Materials Sciences and Engineering Division and Chemical Sciences, Geosciences, and Biosciences Division, of the U.S. Department of Energy under Contract No. DE-AC02-05CH11231. 


\section{References}

[1] G. A. Somorjai, Introduction to Surface Chemistry and Catalysis, Wiley, New York, 1994.

[2] G. Ertl and H. J. Freund, Physics Today 1999, 52, 32-38.

[3] G. A. Somorjai and J. Y. Park, Physics Today 2007, 60, 48-53.

[4] X. S. Liu, C. N. Kim, J. Yang, R. Jemmerson and X. D. Wang, Cell 1996, 86, $147-$ 157.

[5] W. S. Caughey, G. A. Smythe, D. H. Okeeffe, J. E. Maskasky and M. L. Smith, Journal of Biological Chemistry 1975, 250, 7602-7622.

[6] N. Tian, Z. Y. Zhou, S. G. Sun, Y. Ding and Z. L. Wang, Science 2007, 316, 732-735. [7] S. H. Kim and G. A. Somorjai, Proceedings of the National Academy of Sciences of the United States of America 2006, 103, 15289-15294.

[8] H. Song, R. M. Rioux, J. D. Hoefelmeyer, R. Komor, K. Niesz, M. Grass, P. D. Yang and G. A. Somorjai, Journal of the American Chemical Society 2006, 128, 3027-3037.

[9] H. Lee, S. E. Habas, S. Kweskin, D. Butcher, G. A. Somorjai and P. D. Yang, Angewandte Chemie-International Edition 2006, 45, 7824-7828.

[10] A. T. Bell, Science 2003, 299, 1688-1691.

[11] H. J. Freund, H. Kuhlenbeck, J. Libuda, G. Rupprechter, M. Baumer and H. Hamann, Topics in Catalysis 2001, 15, 201-209.

[12] P. L. J. Gunter, J. W. Niemantsverdriet, F. H. Ribeiro and G. A. Somorjai, Catalysis Reviews-Science and Engineering 1997, 39, 77-168.

[13] G. A. Somorjai, A. M. Contreras, M. Montano and R. M. Rioux, Proceedings of the National Academy of Sciences of the United States of America 2006, 103, 10577-10583. [14] C. T. Kresge, M. E. Leonowicz, W. J. Roth, J. C. Vartuli and J. S. Beck, Nature 1992, 359, 710-712.

[15] P. B. Weisz, Pure and Applied Chemistry 1980, 52, 2091-2103.

[16] D. Y. Zhao, J. L. Feng, Q. S. Huo, N. Melosh, G. H. Fredrickson, B. F. Chmelka and G. D. Stucky, Science 1998, 279, 548-552.

[17] D. Zhao, P. Yang, N. Melosh, J. Feng, B. F. Chmelka and G. D. Stucky, Advanced Materials 1998, 10, 1380-+.

[18] A. Corma, Chemical Reviews 1997, 97, 2373-2419.

[19] A. Corma, V. Fornes, M. T. Navarro and J. Perezpariente, Journal of Catalysis 1994, $148,569-574$.

[20] T. Blasco, A. Corma, M. T. Navarro and J. P. Pariente, Journal of Catalysis 1995, $156,65-74$.

[21] J. Grunes, A. Zhu and G. A. Somorjai, Chemical Communications 2003, 2257-2260.

[22] C. T. Campbell, Surface Science Reports 1997, 27, 1-111.

[23] M. Valden, X. Lai and D. W. Goodman, Science 1998, 281, 1647-1650.

[24] C. B. Duke, Chemical Reviews 1996, 96, 1237-1259.

[25] G. S. Blackman, C. T. Kao, B. E. Bent, C. M. Mate, M. A. Vanhove and G. A. Somorjai, Surface Science 1988, 207, 66-88.

[26] M. A. Van Hove and G. A. Somorjai, Journal of Molecular Catalysis a-Chemical 1998, 131, 243-257.

[27] M. Salmeron, R. J. Gale and G. A. Somorjai, Journal of Chemical Physics 1977, 67, 5324-5334. 
[28] S. L. Bernasek, W. J. Siekhaus and G. A. Somorjai, Physical Review Letters 1973, 30, 1202-1204.

[29] N. Materer, U. Starke, A. Barbieri, R. Doll, K. Heinz, M. A. Vanhove and G. A. Somorjai, Surface Science 1995, 325, 207-222.

[30] J. G. Roberts, S. Hoffer, M. A. Van Hove and G. A. Somorjai, Surface Science 1999, 437, $75-85$.

[31] G. A. Somorjai, R. L. York, D. Butcher and J. Y. Park, Physical Chemistry Chemical Physics 2007, 9, 3500-3513.

[32] Y. R. Shen, Annual Review of Physical Chemistry 1989, 40, 327-350.

[33] Y. R. Shen, Nature 1989, 337, 519-525.

[34] X. C. Su, P. S. Cremer, Y. R. Shen and G. A. Somorjai, Physical Review Letters 1996, 77, 3858-3860.

[35] J. A. Jensen, K. B. Rider, M. Salmeron and G. A. Somorjai, Physical Review Letters 1998, 80, 1228-1231.

[36] B. L. M. Hendriksen and J. W. M. Frenken, Physical Review Letters 2002, 89.

[37] S. R. Longwitz, J. Schnadt, E. K. Vestergaard, R. T. Vang, E. Laegsgaard, I.

Stensgaard, H. Brune and F. Besenbacher, Journal of Physical Chemistry B 2004, 108, 14497-14502.

[38] B. J. McIntyre, M. Salmeron and G. A. Somorjai, Journal of Vacuum Science \& Technology a-Vacuum Surfaces and Films 1993, 11, 1964-1968.

[39] A. L. Marsh, K. A. Becraft and G. A. Somorjai, Journal of Physical Chemistry B 2005, 109, 13619-13622.

[40] G. A. Somorjai, K. M. Bratlie, M. O. Montano and J. Y. Park, Journal of Physical Chemistry B 2006, 110, 20014-20022.

[41] P. S. Cremer, X. C. Su, Y. R. Shen and G. A. Somorjai, Journal of the American Chemical Society 1996, 118, 2942-2949.

[42] M. Montano, M. Salmeron and G. A. Somorjai, Surface Science 2006, 600, 18091816.

[43] G. A. Somorjai and R. M. Rioux, Catalysis Today 2005, 100, 201-215.

[44] A. M. Contreras, X. M. Yan, S. Kwon, J. Bokor and G. A. Somorjai, Catalysis Letters 2006, 111, 5-13.

[45] Y. Zhang, M. E. Grass, S. E. Habas, F. Tao, T. Zhang, P. Yang and G. A. Somorjai, Journal of Physical Chemistry C 2007, 111, 12243-12253.

[46] H. Song, F. Kim, S. Connor, G. A. Somorjai and P. D. Yang, Journal of Physical Chemistry B 2005, 109, 188-193.

[47] G. D. Stucky and J. E. Macdougall, Science 1990, 247, 669-678.

[48] K. M. Bratlie, H. Lee, K. Komvopoulos, P. Yang and G. A. Somorjai, Nano Letters 2007, 7, 3097-3101.

[49] J. Y. Park, Y. Zhang, M. Grass, T. Zhang and G. A. Somorjai, Nano Letters 2008, in press.

[50] G. M. Schwab, Angewandte Chemie-International Edition 1967, 6, 375-\&.

[51] A. Boffa, C. Lin, A. T. Bell and G. A. Somorjai, Journal of Catalysis 1994, 149, 149-158.

[52] S. J. Tauster, S. C. Fung and R. L. Garten, Journal of the American Chemical Society 1978, 100, 170-175. 
[53] L. Hellberg, J. Stromquist, B. Kasemo and B. I. Lundqvist, Physical Review Letters 1995, 74, 4742-4745.

[54] Y. H. Huang, C. T. Rettner, D. J. Auerbach and A. M. Wodtke, Science 2000, 290, 111-114.

[55] H. Nienhaus, Surface Science Reports 2002, 45, 3-78.

[56] X. Z. Ji, A. Zuppero, J. M. Gidwani and G. A. Somorjai, Nano Letters 2005, 5, 753756.

[57] J. Y. Park and G. A. Somorjai, Journal of Vacuum Science \& Technology B 2006, 24, 1967-1971.

[58] J. Y. Park and G. A. Somorjai, Chemphyschem 2006, 7, 1409-1413.

[59] K. Hayek, M. Fuchs, B. Klotzer, W. Reichl and G. Rupprechter, Topics in Catalysis 2000, 13, 55-66.

[60] B. Jenewein, M. Fuchs and K. Hayek, Surface Science 2003, 532, 364-369.

[61] G. Rupprechter, G. Seeber, H. Goller and K. Hayek, Journal of Catalysis 1999, 186, 201-213.

[62] S. J. Kweskin, R. M. Rioux, S. E. Habas, K. Komvopoulos, P. Yang and G. A. Somorjai, Journal of Physical Chemistry B 2006, 110, 15920-15925.

[63] A. D. Smigelskas and E. O. Kirkendall, Transactions of the American Institute of Mining and Metallurgical Engineers 1947, 171, 130-142.

[64] Y. D. Yin, R. M. Rioux, C. K. Erdonmez, S. Hughes, G. A. Somorjai and A. P. Alivisatos, Science 2004, 304, 711-714.

[65] E. V. Shevchenko, D. V. Talapin, N. A. Kotov, S. O'Brien and C. B. Murray, Nature 2006, 439, 55-59. 


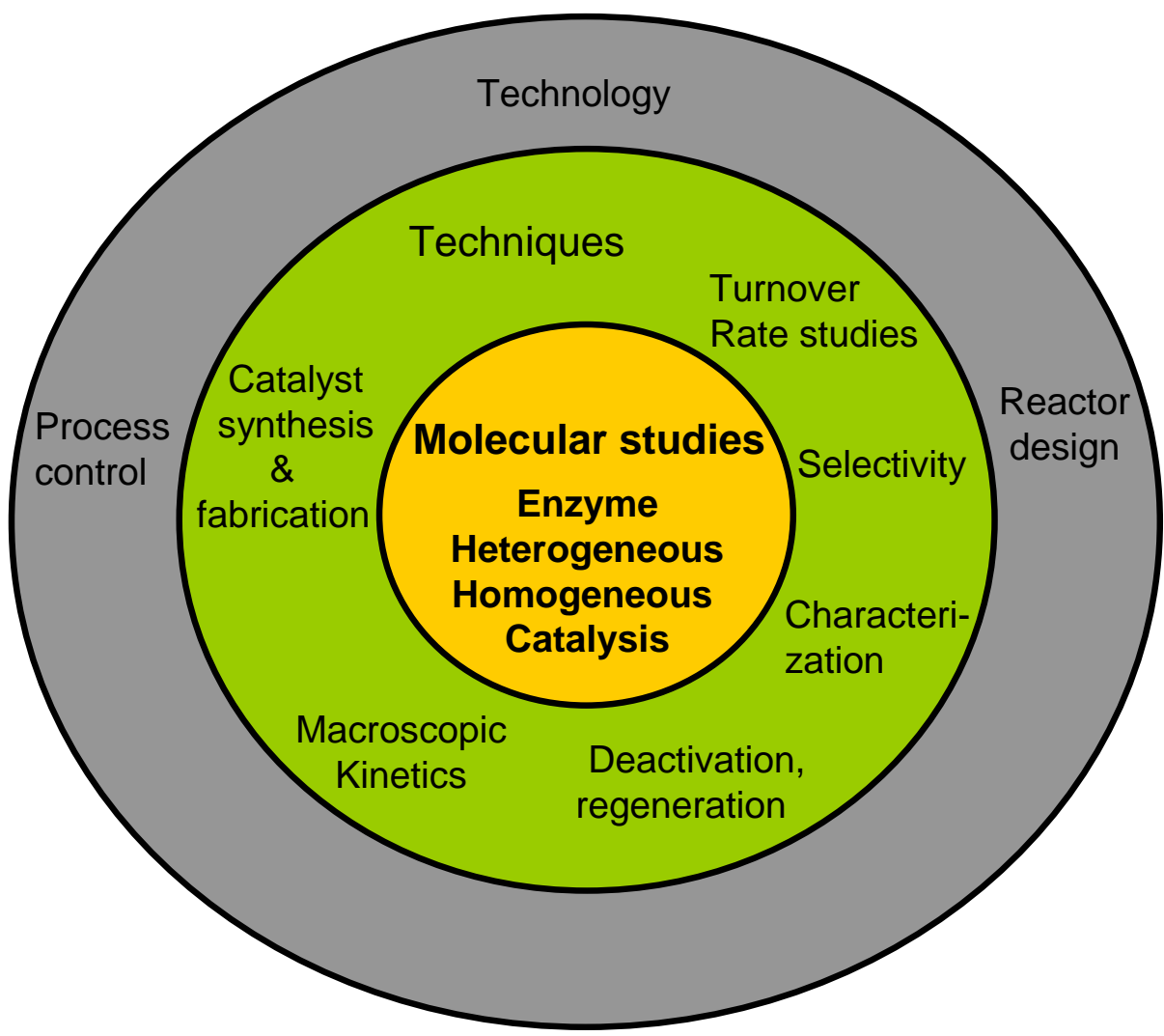

Figure 1. (Color online) Layers of catalysis from technologies to molecular sciences. 
(a) enzyme

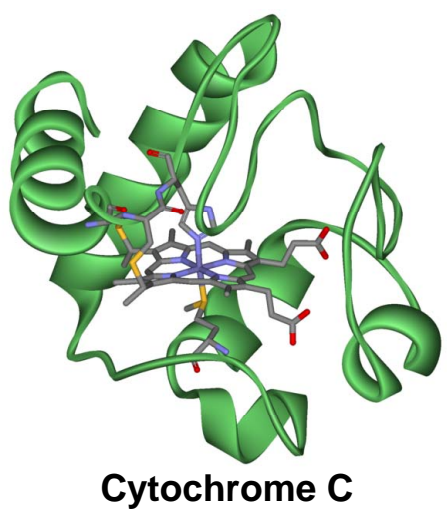

Size: $\sim 4 \mathrm{~nm}, 100$ amino acids

Molecular weight: $\sim 12,000$ daltons (b) Homogeneous

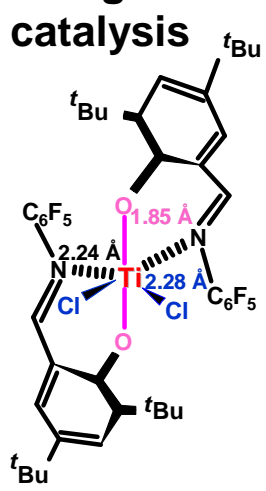

Single-site olefin polymerization catalyst

Size : $\sim 1.6 \mathrm{~nm}$

\section{(c) Heterogeneous catalysis}
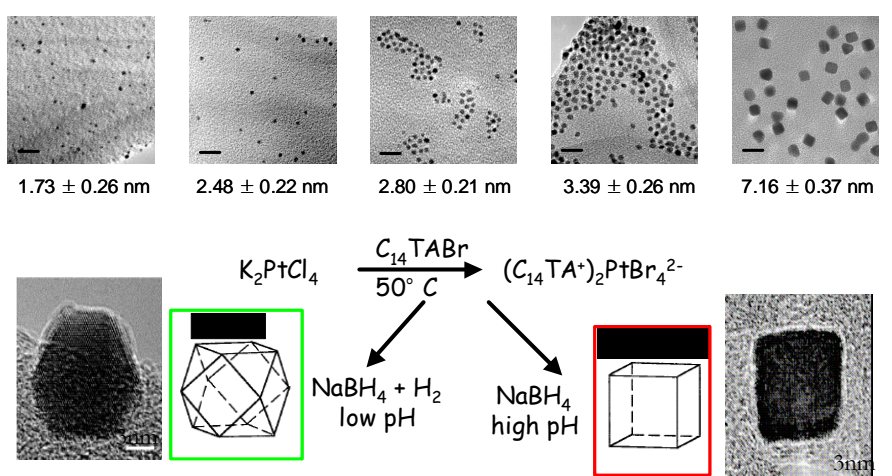

$$
\mathrm{K}_{2} \mathrm{P}+\mathrm{Cl}_{4}
$$

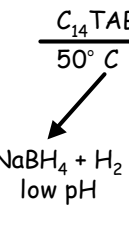

Cuboctahedra
$\left(C_{14} T A^{+}\right)_{2} P+B r_{4}{ }^{2-}$

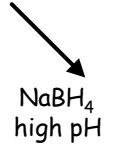

high pH

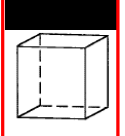

Cubes $\{100\}$

Pt Nanoparticles with controlled size (1-7nm) and shape

Figure 2. (Color online) (a) The Cytochrome $\mathrm{C}$ molecule. (b) Titanium-based single site homogeneous polymerization catalyst (c) Platinum monodispersed nanoparticles of 1-7 nm size and well-controlled cubic or cuboctahedra shapes. 
(a) External Surfaces

Single Crystal Surfaces

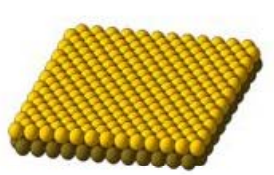

fcc (111)

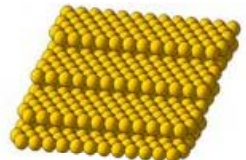

fcc (755)

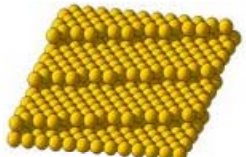

fcc $(10,8,7)$

(b) Internal Surfaces

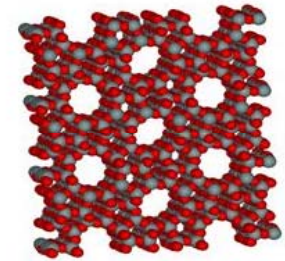

Zeolite (Silicalite)

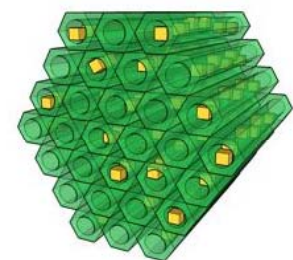

Nanoparticles in Mesoporous Silica (SBA-15)

Pore size $<2 \mathrm{~nm}$ - Pores are ordered with interconnections

- Pores of $2-50 \mathrm{~nm}$ with narrow size distribution - Pores are ordered
(C) Nanoparticle Surfaces

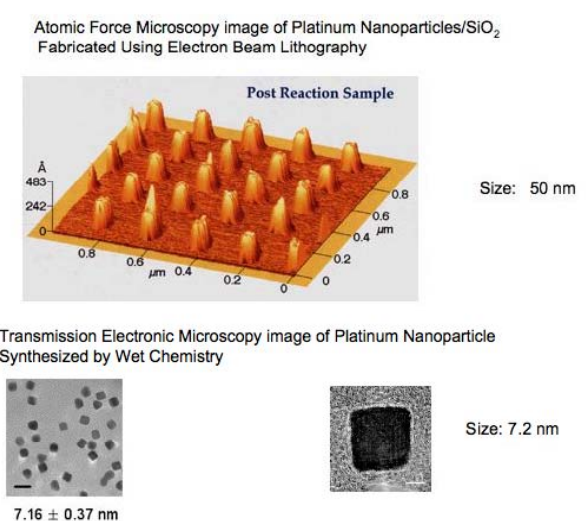

Figure 3. (Color online) Three types of surfaces (a) external surfaces such as single crystals and plant surfaces (green leaf) (b) internal surfaces where most of the surface area is located inside the micropores or mesopores, and (c) nanoparticles of platinum made by electron beam lithography or nanoparticles synthesized in colloidal solutions. 


\title{
Evolution of Surface Science
}

\section{Nanosciences}

Monodispersed nanoparticles 2D and 3D

\begin{abstract}
Applications in Catalysis, Tribology, Polymers,
Biointerfaces, Microelectronics, Energy Conversions, Environmental Chemistry, Electrochemistry, Corrosion
\end{abstract}

Surface Instruments at High Pressures, Liquid Interfaces (STM, SFG, AFM, QCM, RAIRS)

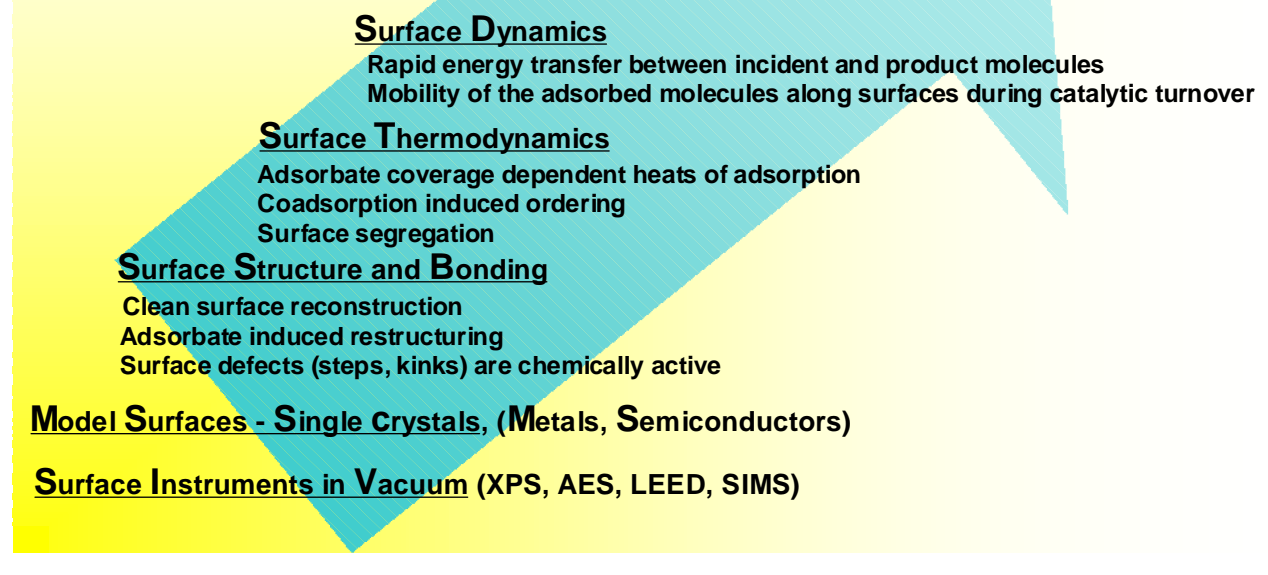

Figure 4. (Color online) Schematic showing the evolution of modern surface science. 

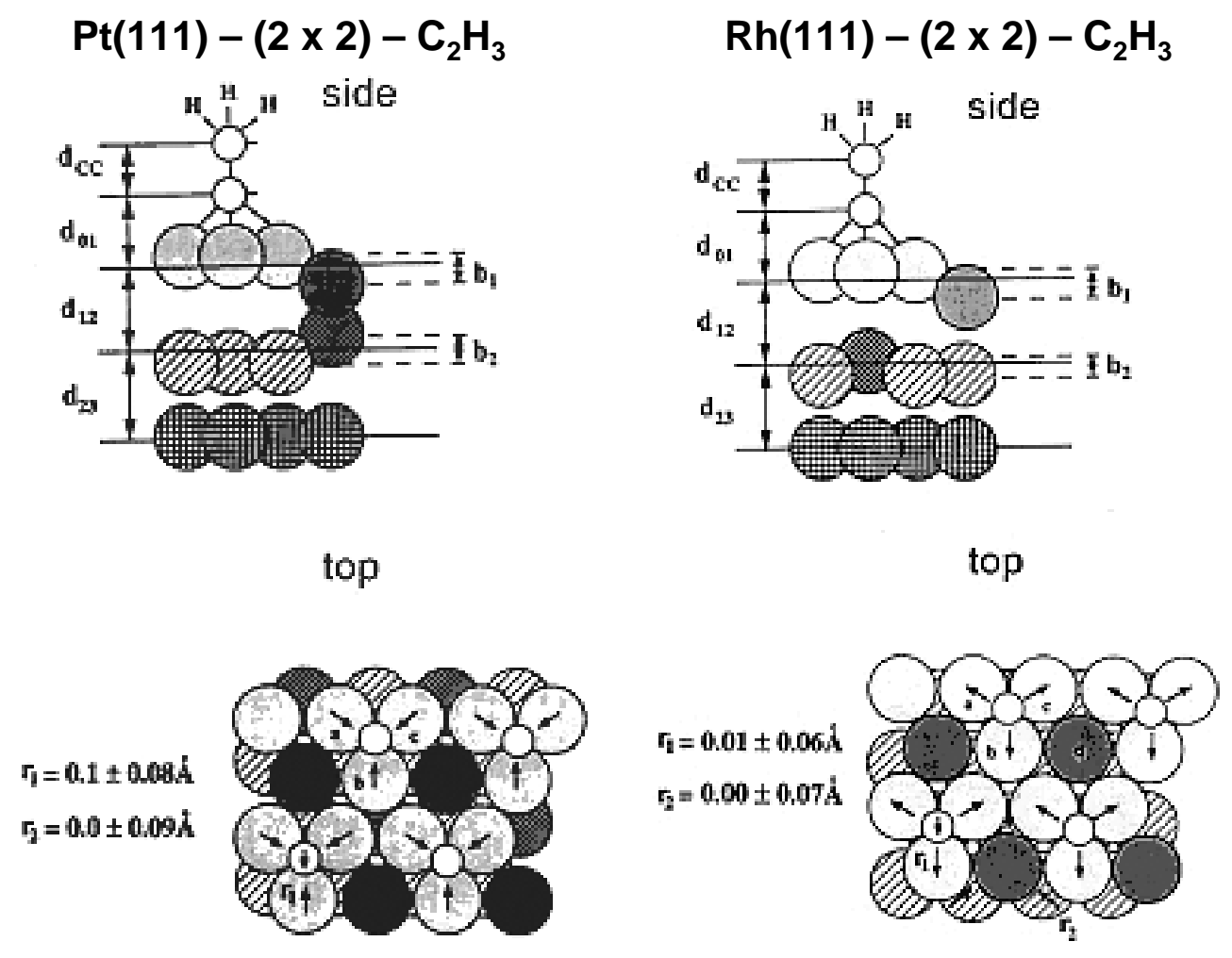

Figure 5. Low energy electron diffraction studies reveal that the bond order of the adsorbed ethylene and adsorbate-induced surface restructuring on the platinum and rhodium (111) crystal faces. 
(a)

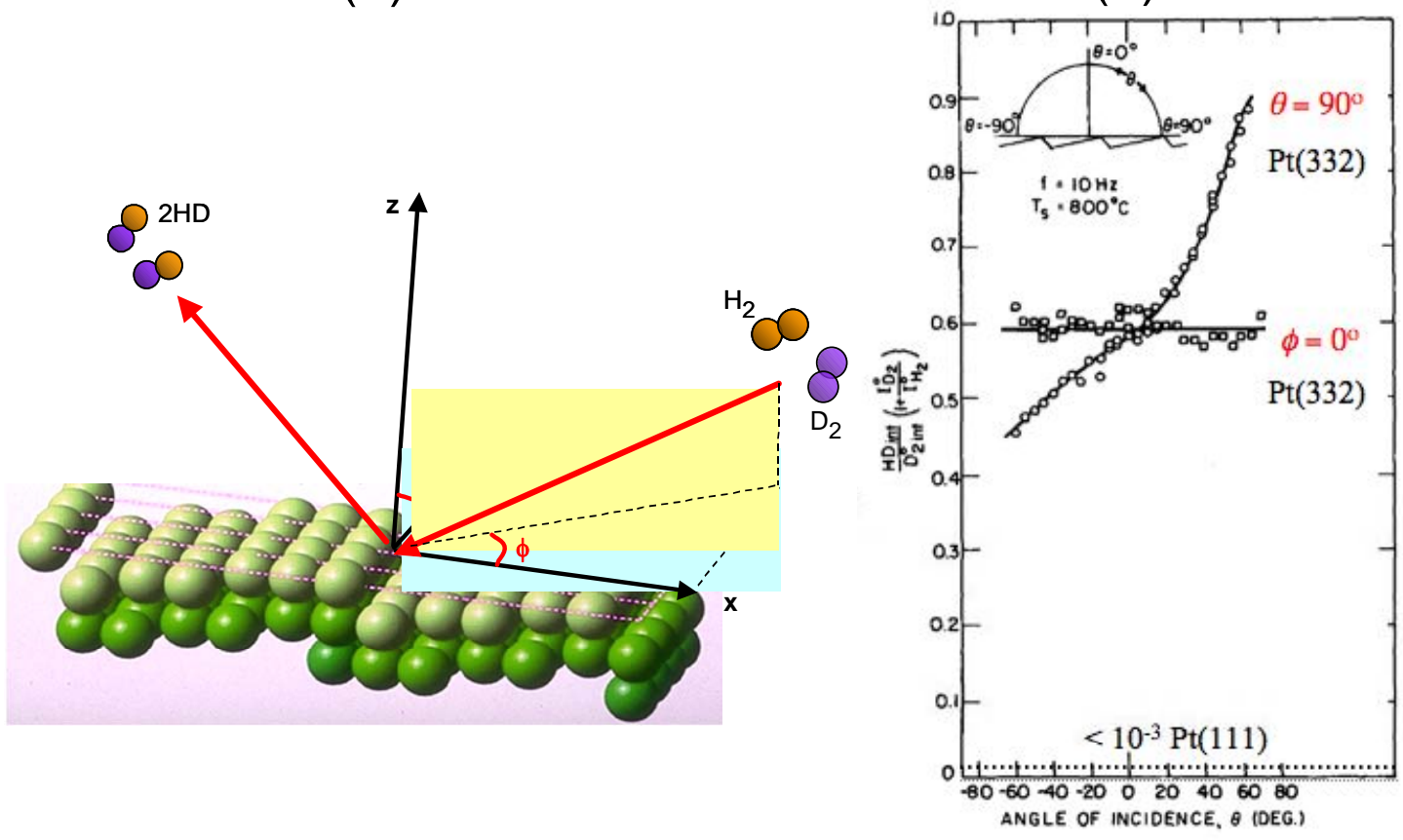

(b)

Figure 6. (Color online) Molecular beam scattering studies of $\mathrm{H}_{2}-\mathrm{D}_{2}$ exchange on $\operatorname{Pt}(332)$ surface, showing that atomic steps on metal surfaces break chemical bonds, in this case hydrogen-hydrogen bonds, with unit reaction probability. (a) schematic defining the geometry of the incident angle (polar $\theta$ and azimuthal $\phi$ ) of the molecular beam with respect to a stepped surface. (b) HD production as a function of angle of incidence $\theta$ of the molecular beam normalized to the incident $\mathrm{D}_{2}$ intensity. 

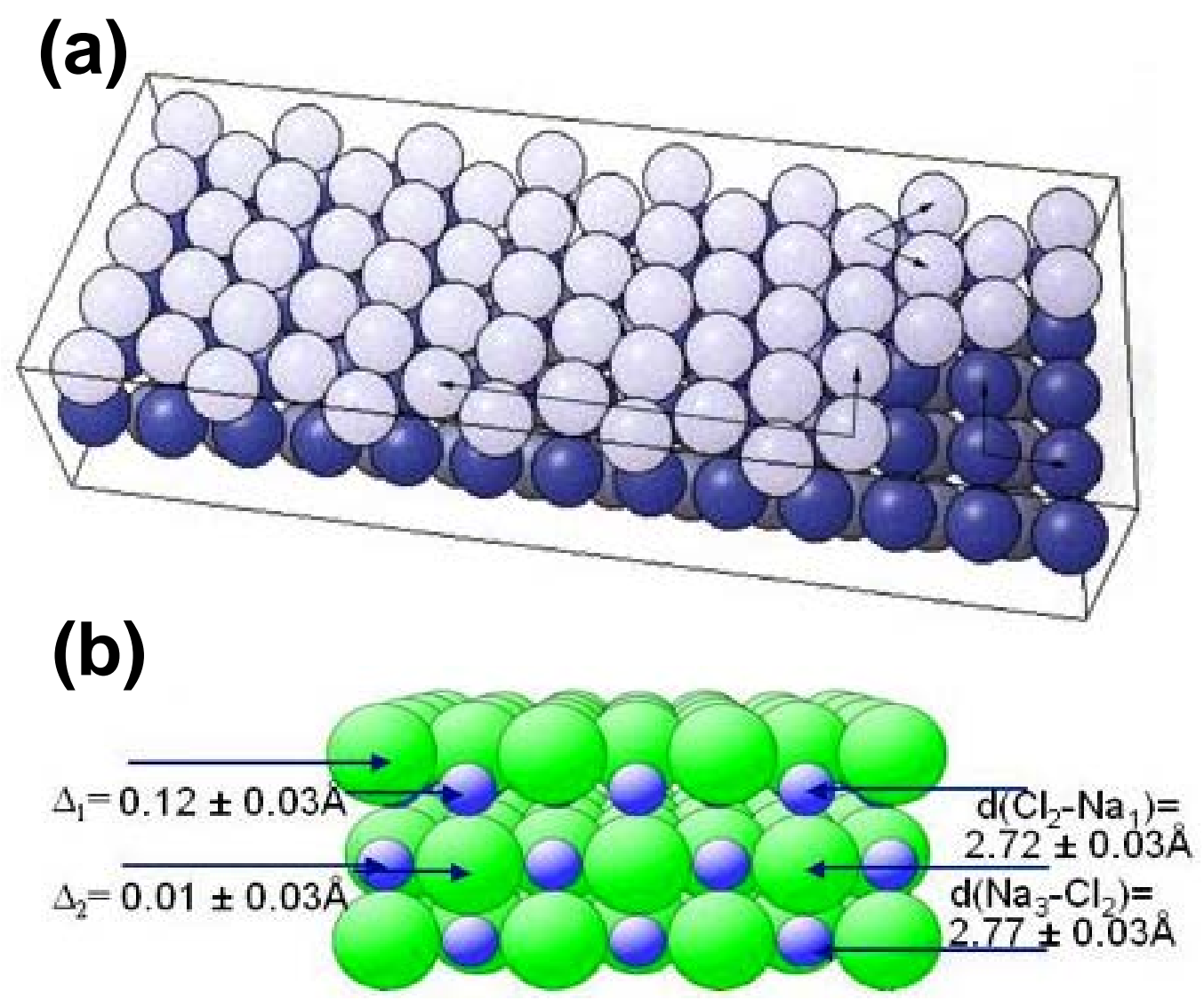

Figure 7. (Color online) Flat, high density clean surfaces of many substances also restructure where the surface atoms move into new locations for (a) platinum (100) surface and (b) sodium chloride (100). 
(a)
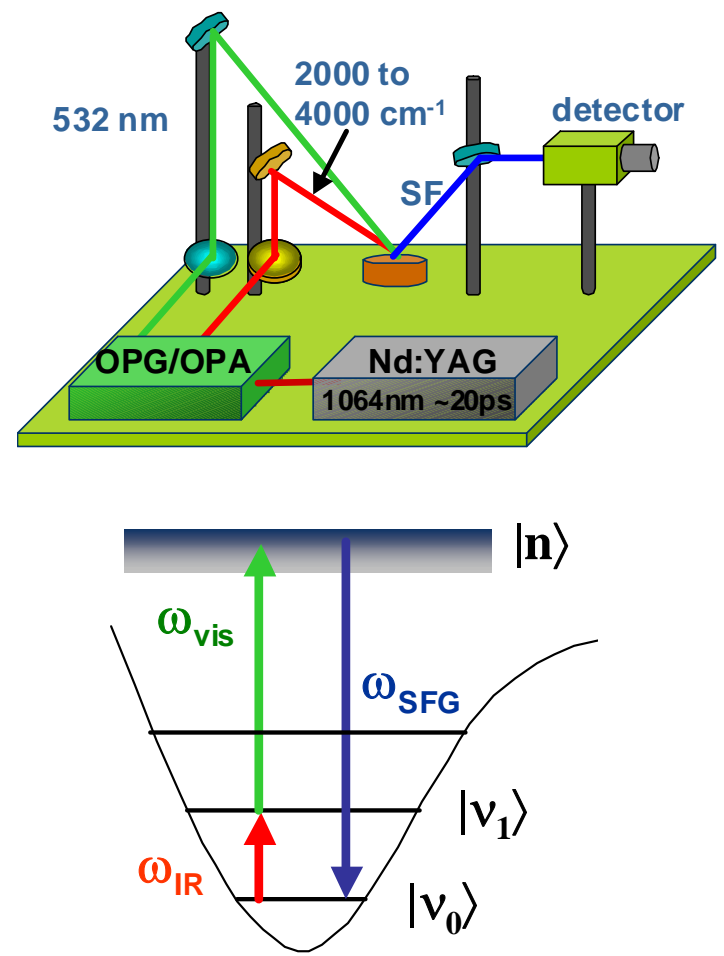

(b)

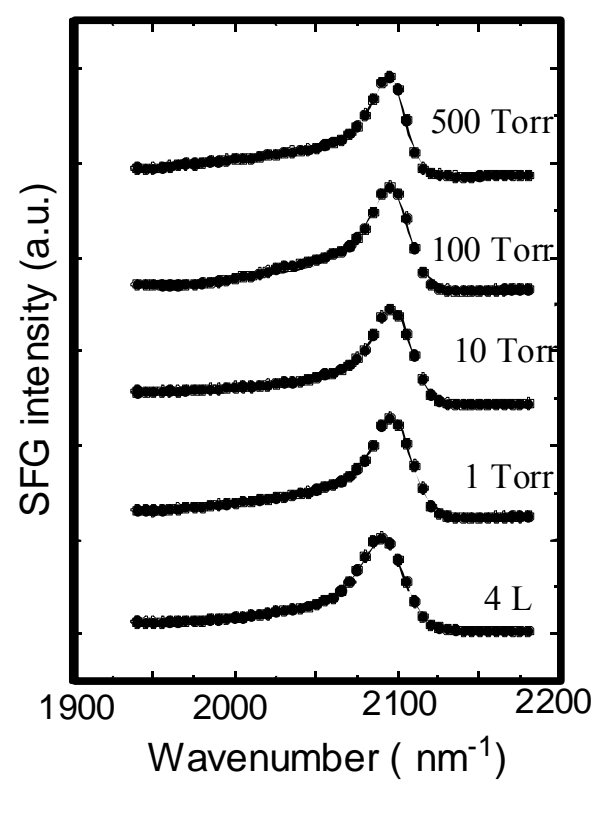

Figure 8. (Color online) (a) Schematic of SFG. a vibrational spectroscopic tool for probing intermediate species during the catalytic reaction. (b) SFG spectra of $\mathrm{CO}$ on $\mathrm{Pt}$ (557) over 12 orders of magnitude in pressure. 
(a)

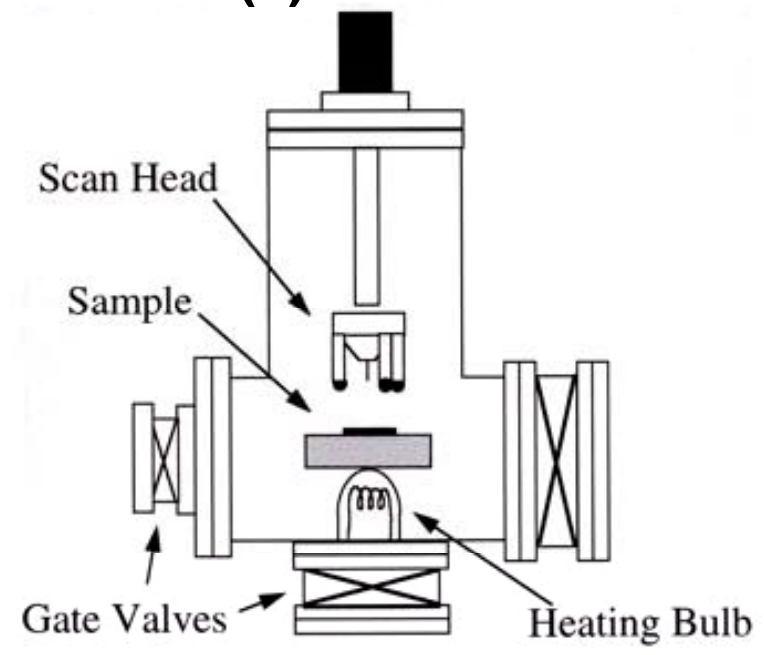

Pressure range:

$5 \times 10^{-10}$ Torr to 1 atm

Temperature range: $25^{\circ} \mathrm{C}$ to $400{ }^{\circ} \mathrm{C}$ (b)

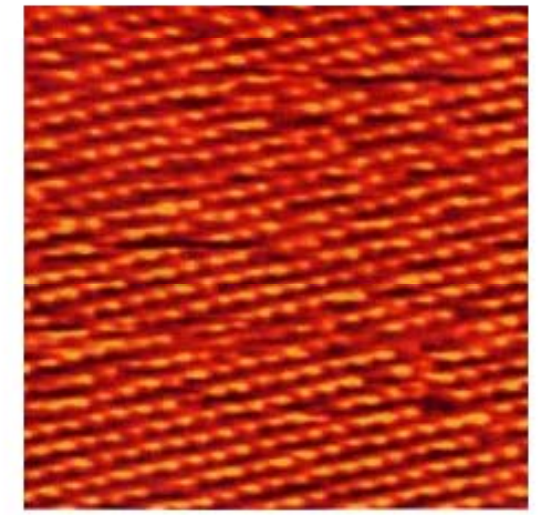

gorgarogrogos:

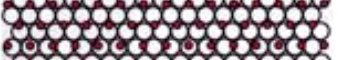

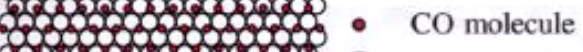

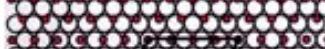

CO molecule $\mathrm{Pt}$ atom

Figure 9. (Color online) (a) Schematic of high pressure STM. (b) STM topographical image of $\mathrm{Pt}(111)$ surface in 200 Torr $\mathrm{CO}$ and a possible model of the incommensurate $\mathrm{CO}$ overlayer in relation to the $\mathrm{Pt}(111)$ lattice. 


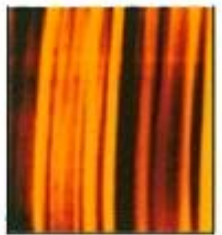

$730 \AA \times 700 \AA$

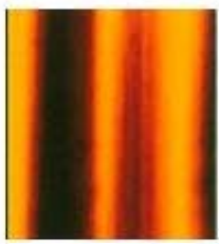

$900 \AA \times 780 \AA$

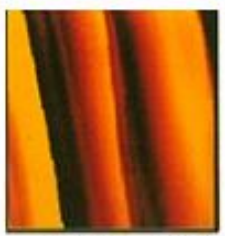

$770 \AA \times 740 \AA$

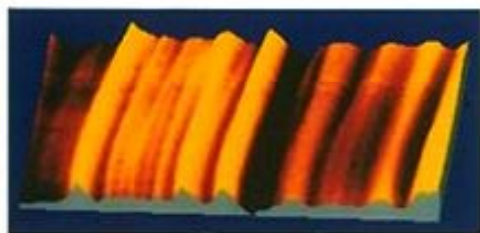

Hydrogen: $1.7 \mathrm{~atm}$.

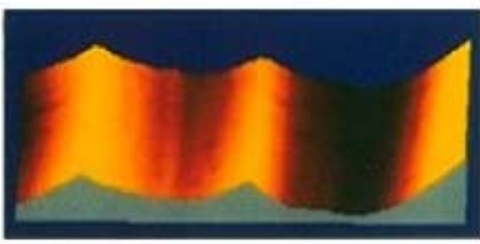

Oxygen: $1 \mathrm{~atm}$.

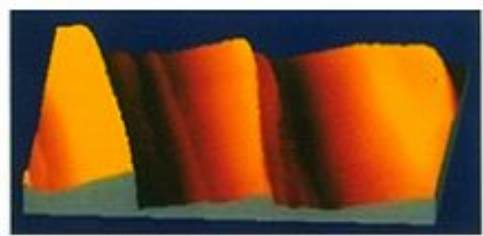

Carbon Monoxide: $1 \mathrm{~atm}$.

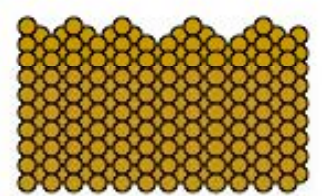

"nested" missing-row reconstructions

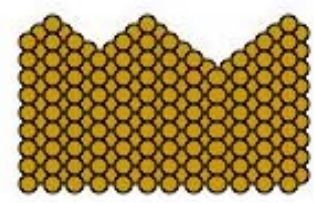

fcc (111) microfacets

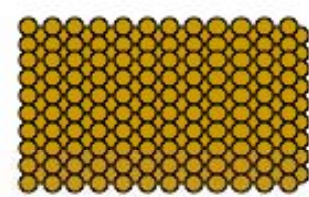

Unreconstructed (111) terraces separated by multiple height steps

Figure 10. (Color online) In-situ STM images revealing adsorbate-induced reconstruring of $\mathrm{Pt}$ (110) surface in 1.7 atm hydrogen $(73 \mathrm{~nm} \times 70 \mathrm{~nm}), 1.0 \mathrm{~atm}$ oxygen $(90 \mathrm{~nm} \times 78 \mathrm{~nm})$ and $1.0 \mathrm{~atm}$ carbon monoxide (77 $\mathrm{nm} \times 74 \mathrm{~nm})$. 
(a)

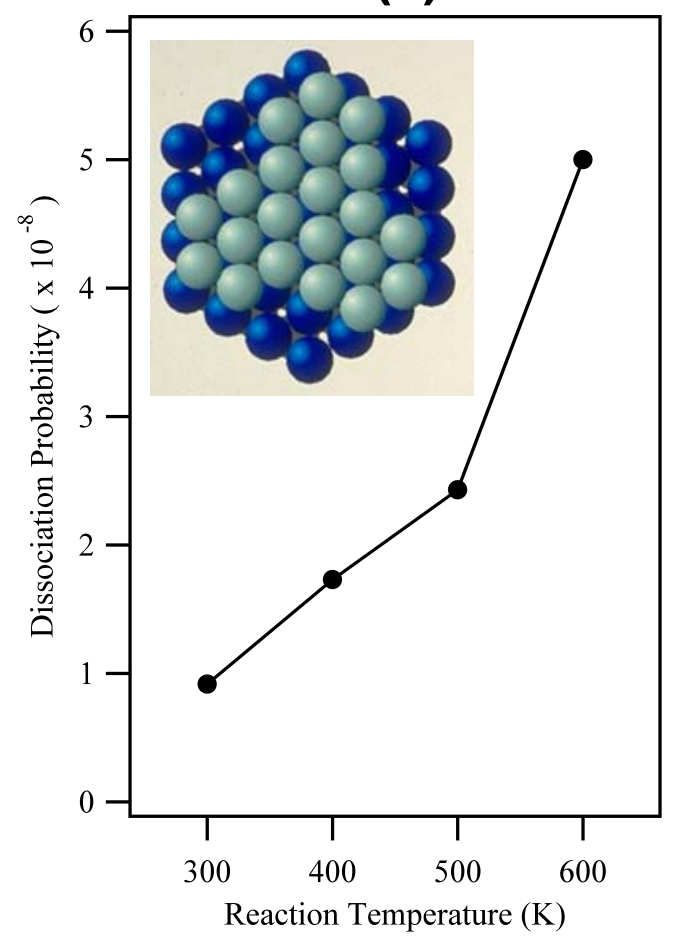

(b)

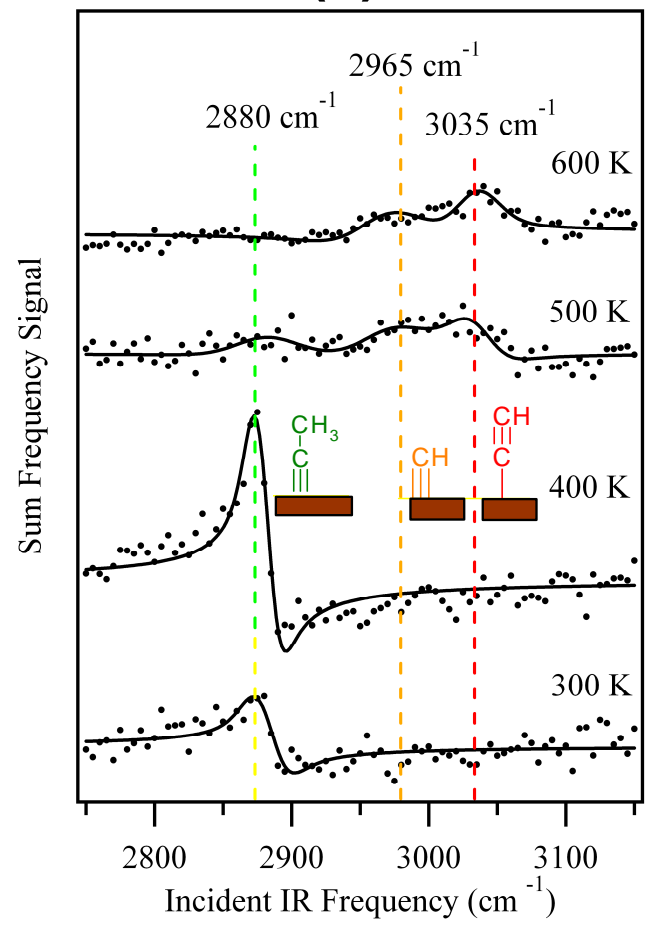

Figure 11. (Color online) (a) Methane C-H dissociation probabilities derived from carbon coverages measured by AES for selected reaction temperatures. (b) SFG spectra recorded after reaction of 1 Torr of methane for $60 \mathrm{~s}$ with the $\operatorname{Pt}(111)$ surface at selected reaction temperatures. Markers represent the experimental data, and solid lines represent the curve fits. Insets show intermediates for methane dissociative adsorption and reaction of methane-derived species on the $\operatorname{Pt}(111)$. 
(a)

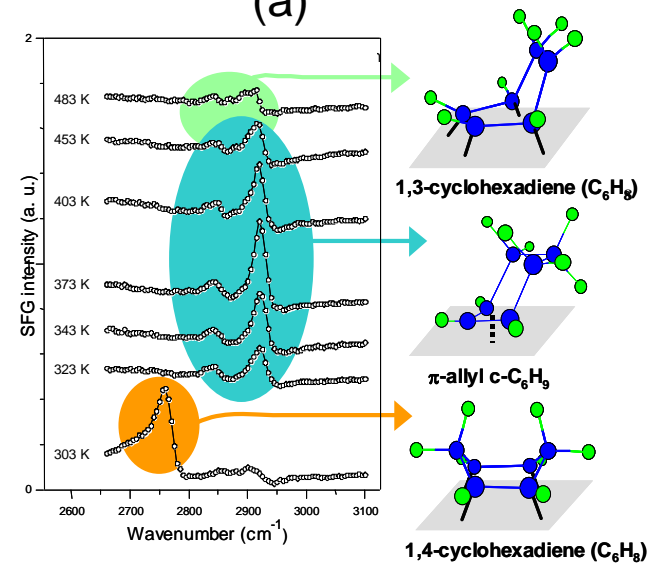

(b)

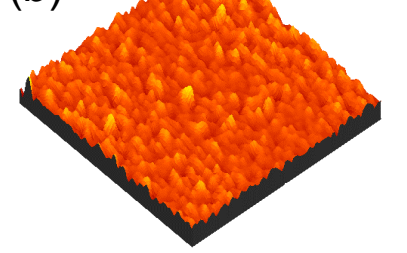

(c)

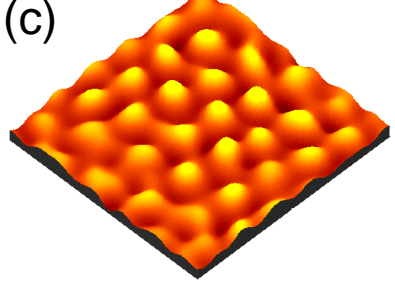

Figure 12. (Color online) (a) SFG spectra of cyclohexene hydrogenation to cyclohexane and dehydrogenation to benzene. These two reactions occur simultaneously in excess hydrogen of about 10 Torr and 1.5 Torr of hydrocarbon. SFG vibration spectra reveals that the presence of three different species on the surface in this reactant mixture, 1,4-, 1,3-cyclohexadienes and $\pi$ allyl c- $\mathrm{C}_{6} \mathrm{H}_{9}$. (b) $70 \AA \times 70 \AA \mathrm{STM}$ images of the $\mathrm{Pt}(111)$ surface at $300 \mathrm{~K}$ in the presence of (b) $200 \mathrm{mTorr}$ of hydrogen, 20 mTorr of cyclohexene. Surface is catalytically active producing both cyclohexane and benzene. (c) $200 \mathrm{mTorr}$ of hydrogen, $20 \mathrm{mTorr}$ of cyclohexene, and 5 mTorr of CO. Surface has been deactivated. 


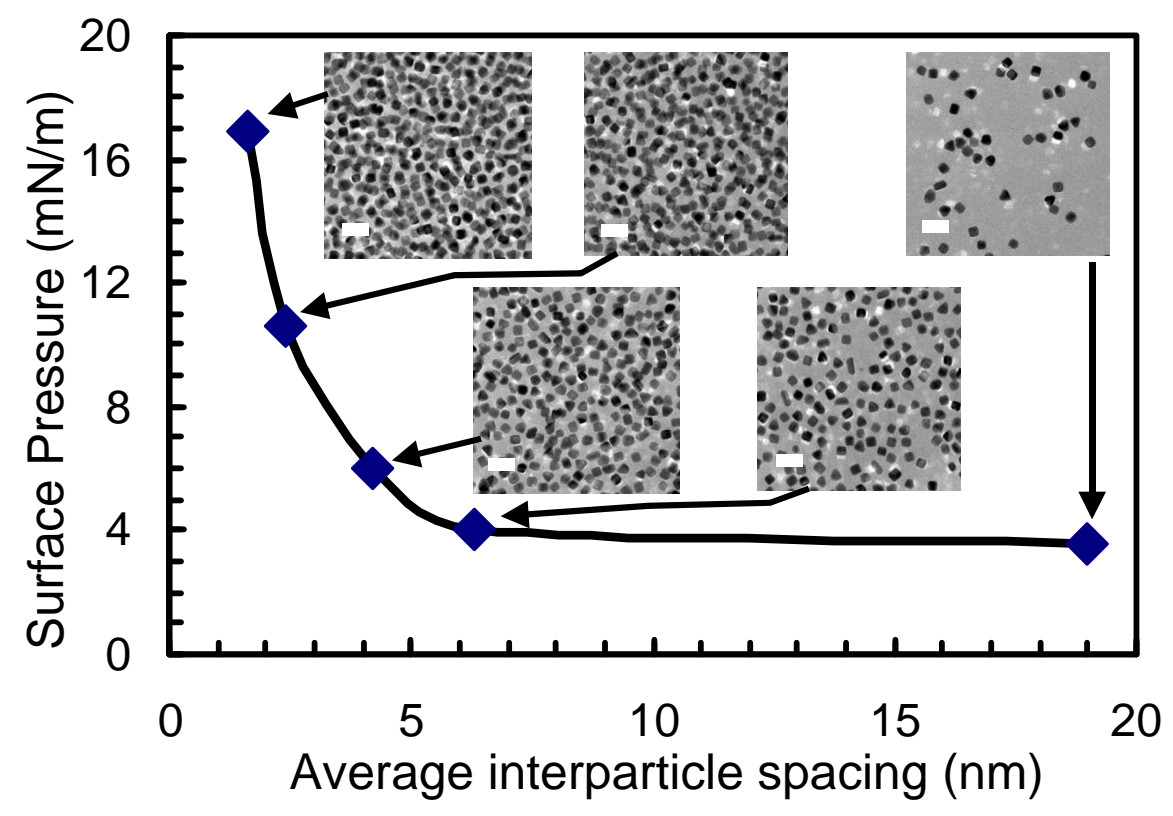

Figure 13. Plot of surface pressure as a function of average interparticle spacing of monodispersed Pt nanoparticle arrays. The surface density of nanoparticles is controlled by the surface pressure. The bars in the TEM images refer to $20 \mathrm{~nm}$. 


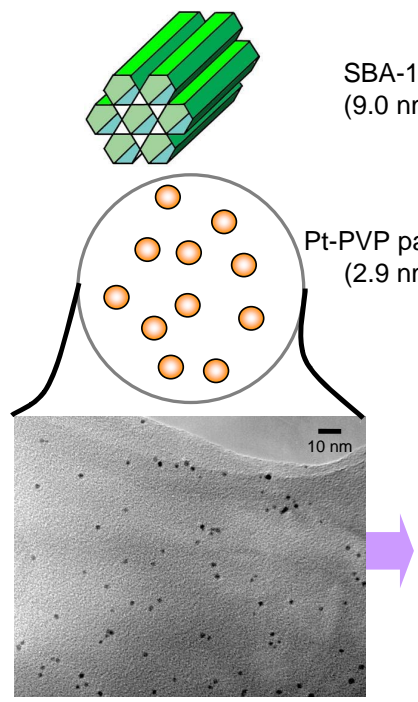

$\mathrm{Pt}(2.6 \mathrm{~nm})-\mathrm{PVP}$

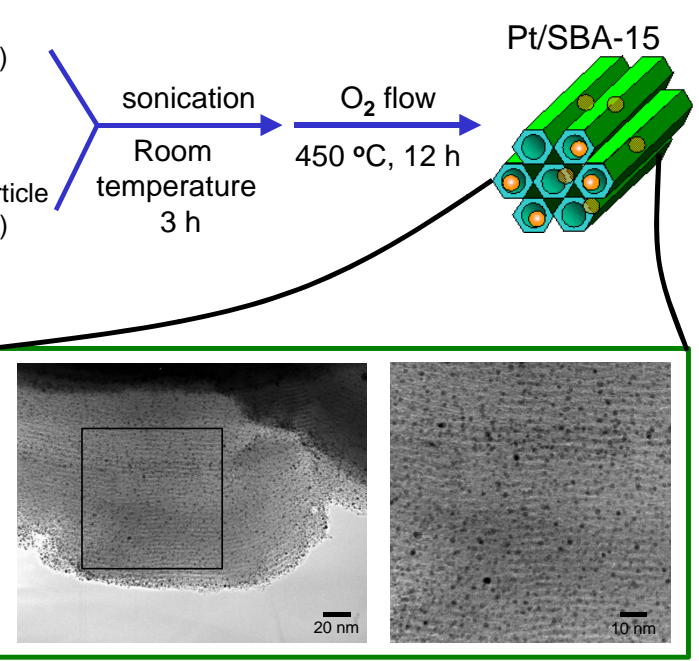

$0.90 \% \operatorname{Pt}(2.6 \mathrm{~nm}) / \mathrm{SBA}-15$

Figure 14. (Color online) TEM images of Pt nanoparticles $(2.6 \mathrm{~nm})$ assembled into SBA-15 silica support by capillary inclusion method. 


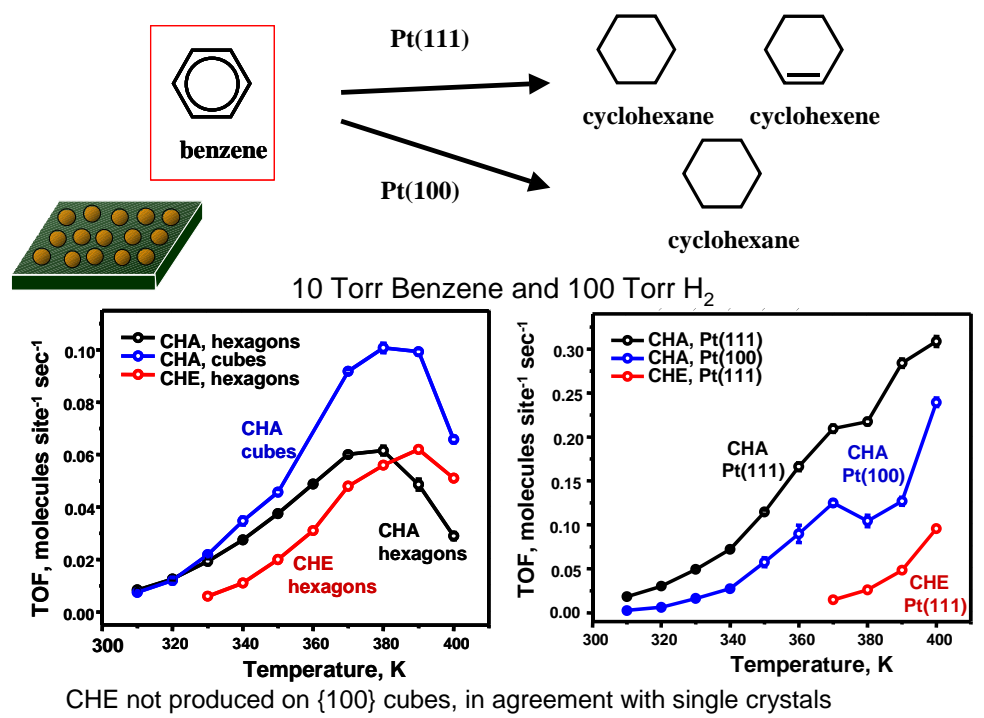

Figure 15. (Color online) Turnover rates of cyclohexane $\left(\mathrm{C}_{6} \mathrm{H}_{12}\right)$ and cyclohexene $\left(\mathrm{C}_{6} \mathrm{H}_{10}\right)$ formation on $\mathrm{Pt}(100)$ and $\mathrm{Pt}(111)$ singlecrystals and TTAB-stabilized cubic and cuboctahedral Pt nanoparticles for 10 Torr $\mathrm{C}_{6} \mathrm{H}_{6}, 100$ Torr $\mathrm{H}_{2}$, and 650 Torr Ar. CHA and $\mathrm{CHE}$ in the plots refers to cyclohexane and cyclohexene, recnertivelv 
(a)

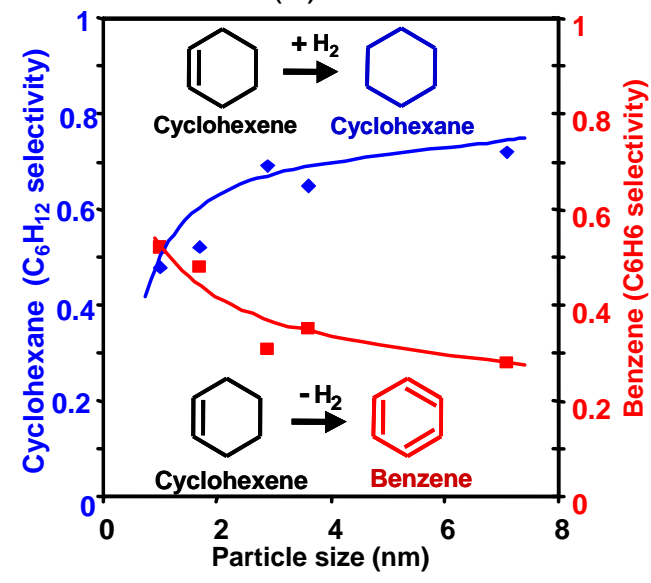

(b)

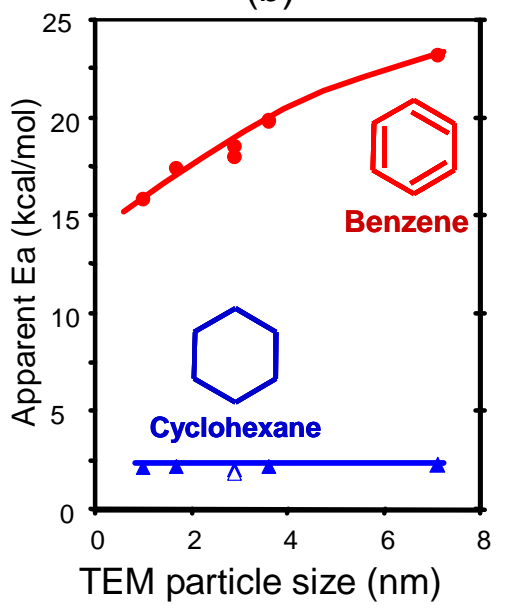

Figure 16. (Color online) (a) The size dependence of Pt nanoparticles on the selectivity of cyclohexene hydrogenation / dehydrogenation. (b) activation energy of cyclohexene hydrogenation / dehydrogenation as a function of particle size. 
(a)

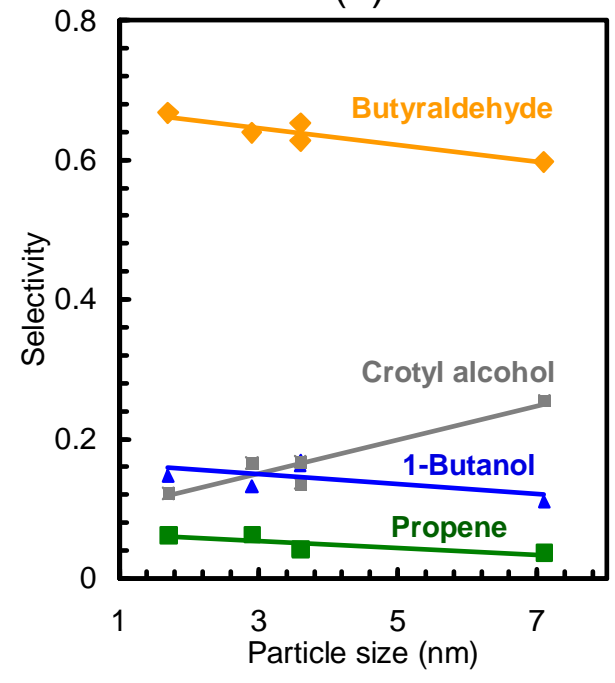

(b)

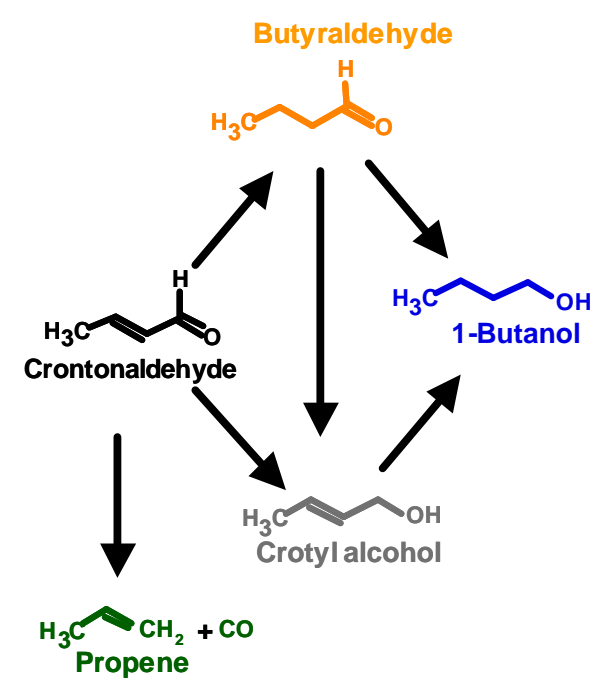

Figure 17. (Color online) (a) Size dependence of Pt nanoparticle on the selectivity in crotonaldehyde hydrogenation and (b) schematics of multipath reactions of crotonaldehyde hydrogenation. 
(a)
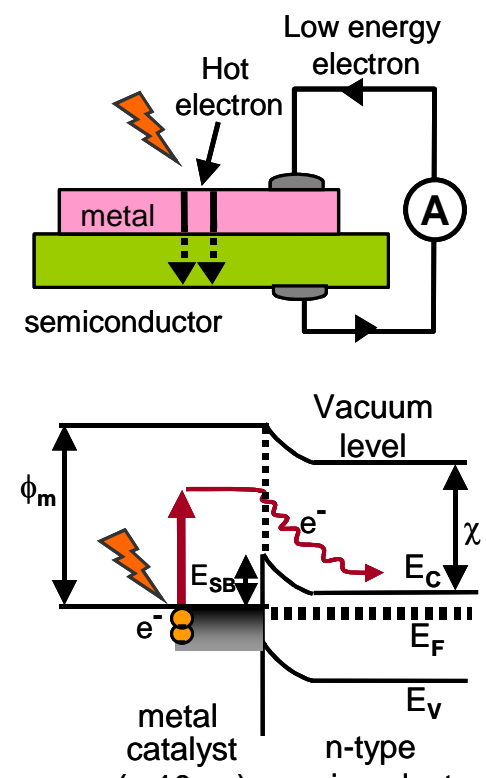

(b)

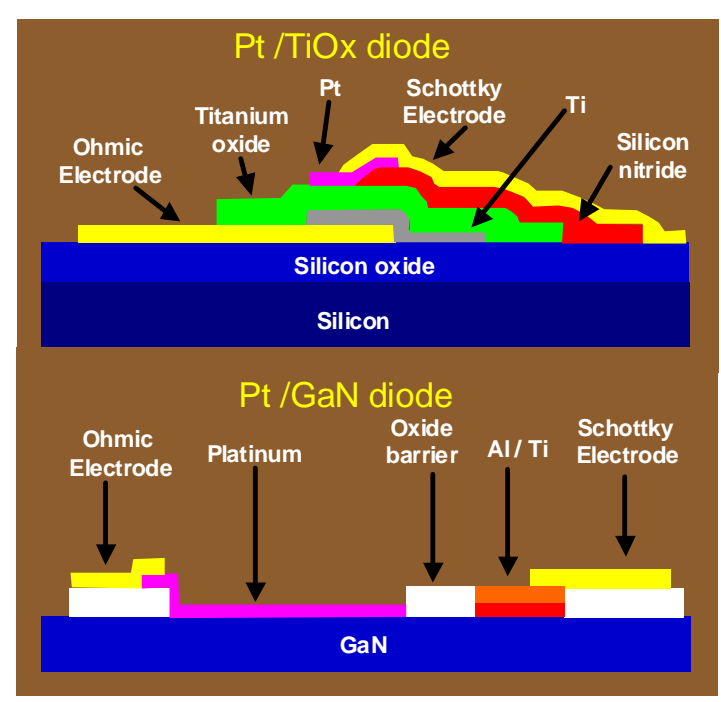

$(<10 \mathrm{~nm})$ semiconductor

Figure 18. (Color online) (a) The schematic and energy diagram of hot electron generation in metal-semiconductor nanodiodes. Schottky barrier is the energy barrier between the metal and semiconductor. The barrier height $\left(E_{\mathrm{SB}}\right)$ is energy difference between the metal work function $\left(\phi_{\mathrm{m}}\right)$ and electron affinity of semiconductor $(\chi)$. The hot electrons overcome the Schottky barrier and turn into low energy electrons in the semiconductor when the excess energy is larger than the Schottky barrier height. (b) Schematic of $\mathrm{Pt} / \mathrm{TiO}_{2}$ and $\mathrm{Pt} / \mathrm{GaN}$ catalytic nanodiodes. 

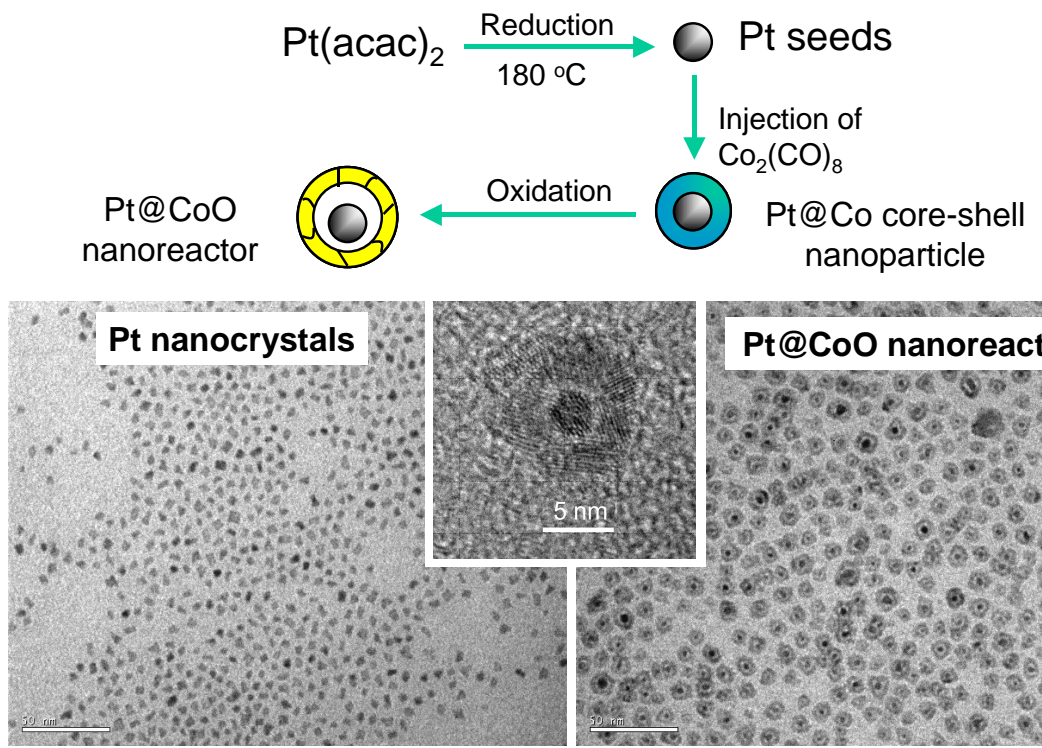

Pt@CoO nanoreactors

Figure 19. (Color online) Schematic of synthesis of $\mathrm{Pt} / \mathrm{CoO}$ nanoreactors, and TEM images of $\mathrm{Pt}$ and $\mathrm{Pt} / \mathrm{CoO}$ nanoreactors. The scale bar in TEM images refer to $50 \mathrm{~nm}$. 